\title{
Different Functional Types of Bipolar Cells Use Different Gap-Junctional Proteins
}

\author{
Bin Lin, Tatjana C. Jakobs, and Richard H. Masland \\ Howard Hughes Medical Institute, Massachusetts General Hospital, Harvard Medical School, Boston, Massachusetts 02114
}

\begin{abstract}
Rod signals are transmitted to ON retinal ganglion cells by means of gap junctions between AII amacrine cells and ON bipolars. The AII amacrine cells are known to express connexin36 (Cx36), but previous studies of $\mathrm{Cx} 36$ in $\mathrm{ON}$ cone bipolars have been ambiguous. Here, we studied bipolar cells in a transgenic mouse line that expresses high levels of green fluorescent protein (GFP) in one type of ON cone bipolar cell. We found strong Cx36 immunostaining in the axon terminals of the GFP-labeled type 357 bipolar cells in both vertical sections and whole mounts of the retina. This finding was confirmed by single-cell immunostaining and single-cell reverse transcription-PCR (RTPCR). As reported previously (Maxeiner et al., 2005), Cx45 was found in some ON bipolar cells, but RT-PCR showed Cx36 and not Cx45 to be expressed by the type 357 bipolar cells. Some of the remaining GFP-negative bipolar cells expressed $\mathrm{Cx} 45$ but not $\mathrm{Cx} 36$. It appears that different types of $\mathrm{ON}$ cone bipolar cells express different connexins at their gap junctions with AII amacrine cells.
\end{abstract}

Key words: mouse; GFP; retina; Cx36; ON bipolar cell; gap junctions

\section{Introduction}

In mammalian retinas, rod signals generated under scotopic light condition are transmitted to the cone system through the AII amacrine cell (Wässle and Boycott, 1991; Strettoi et al., 1992, 1994; Sterling, 1998). AII amacrine cells make gap junctions with neighboring AII amacrines in the most vitreal region of the inner plexiform layer (IPL) and with axon terminals of cone bipolars in sublamina b of the IPL (Kolb and Famiglietti, 1974; Famiglietti and Kolb, 1975; Strettoi et al., 1992; Massey and Mills, 1999).

Connexin36 (Cx36) expression has been demonstrated in both the outer and inner plexiform layers of the mammalian retina (Feigenspan et al., 2001; Mills et al., 2001). It is located in cone photoreceptors and dendrites of OFF cone bipolars in the outer plexiform layer (Feigenspan et al., 2004) and on the dendrites of AII amacrines in the IPL (Feigenspan et al., 2001; Mills et al., 2001). Cx36 is required for gap-junctional communication between pairs of AII amacrines, because dye coupling between AII amacrines is lost in Cx36 knock-out animals. In addition, Güldenagel et al. (2001) and Deans et al. (2002) have shown a loss of scotopic signaling in Cx36 knock-out mice, indicating a clear functional role for $\mathrm{Cx} 36$ in the gap junctions between $\mathrm{ON}$ cone bipolars and AII amacrines.

The composition of this junction is unclear. Feigenspan et al. (2001) did not find immunostaining for Cx36 on axon terminals of recoverin-positive bipolar cells, nor did they find immunoreactivity in morphologically identified bipolar cells after dissociation. They concluded that the gap junction between ON bipolar and AII amacrine must be heterotypic in nature, composed of

\footnotetext{
Received 0ct. 8, 2004; revised June 8, 2005; accepted June 9, 2005. R.H.M. is a Senior Investigator of Research to Prevent Blindness.

Correspondence should be addressed to Dr. Bin Lin, Massachusetts General Hospital, 50 Blossom Street, Wellman 429, Boston, MA 02114. E-mail: blin@helix.mgh.harvard.edu.

DOI:10.1523/JNEUROSCI.1894-05.2005

Copyright $\odot 2005$ Society for Neuroscience $\quad$ 0270-6474/05/256696-06\$15.00/0
}

hemichannels containing $\mathrm{Cx} 36$ on one side and an as yet unidentified connexin on the other side; a recently identified possibility is Cx45 (Maxeiner et al., 2005). In contrast, a Cx36 reporter in a transgenic mouse was clearly expressed in a subset of bipolar cells with axons terminating in the ON layer of the IPL (Deans et al., 2002). The previous results are thus ambiguous.

The issue is of physiological consequence, because this junction is, under scotopic conditions, a major gateway between the visual stimulus and the output of the retina. We wanted to resolve it by taking advantage of the availability of a transgenic mouse line in which one population of ON cone bipolar cells strongly expresses green fluorescent protein (GFP) (Huang et al., 1999). It appears to be bipolar cell type 7 from the study by Ghosh et al. (2004) and type CB4a from the study by Pignatelli and Strettoi (2004). Given the ability to reliably identify this type of bipolar cell, we could study Cx36 expression in intact tissue, dissociated cells, and a PCR product from picked cells. We found that this particular type of ON cone bipolar expresses Cx36.

\section{Materials and Methods}

Retinal preparation. Transgenic mice (357 transgenic mice) were used for the experiments between the ages of 6 and 8 weeks (Huang et al., 1999). Experimental procedures were in accordance with the guidelines of the Subcommittee for Research Animal Care of the Massachusetts General Hospital. Animals were anesthetized with a mixture of ketamine hydrochloride $(30-40 \mathrm{mg} / \mathrm{kg})$ and xylazine $(3-6 \mathrm{mg} / \mathrm{kg})$. The eyes were quickly enucleated, and the retina was dissected free of the vitreous and sclera in carboxygenated Ames medium (Sigma, St. Louis, MO). The isolated retinas were fixed in $4 \%$ paraformaldehyde (PFA) in $0.1 \mathrm{M}$ phosphate buffer (PB), pH 7.4, for $30 \mathrm{~min}$.

For preparation of retinal slices, the retina was removed from the sclera and embedded in 2\% agarose (Sigma) in Ames medium. Slices were cut at $200 \mu \mathrm{m}$ on a vibratome and fixed immediately in $2 \%$ PFA for 3 min. Intracellular injections were performed with sharp borosilicate microelectrodes filled with $10 \mathrm{~mm}$ Alexa Fluor 594 hydrazide (Molecular Probes, Eugene, OR). The dye was injected iontophoretically (5-10 min, 

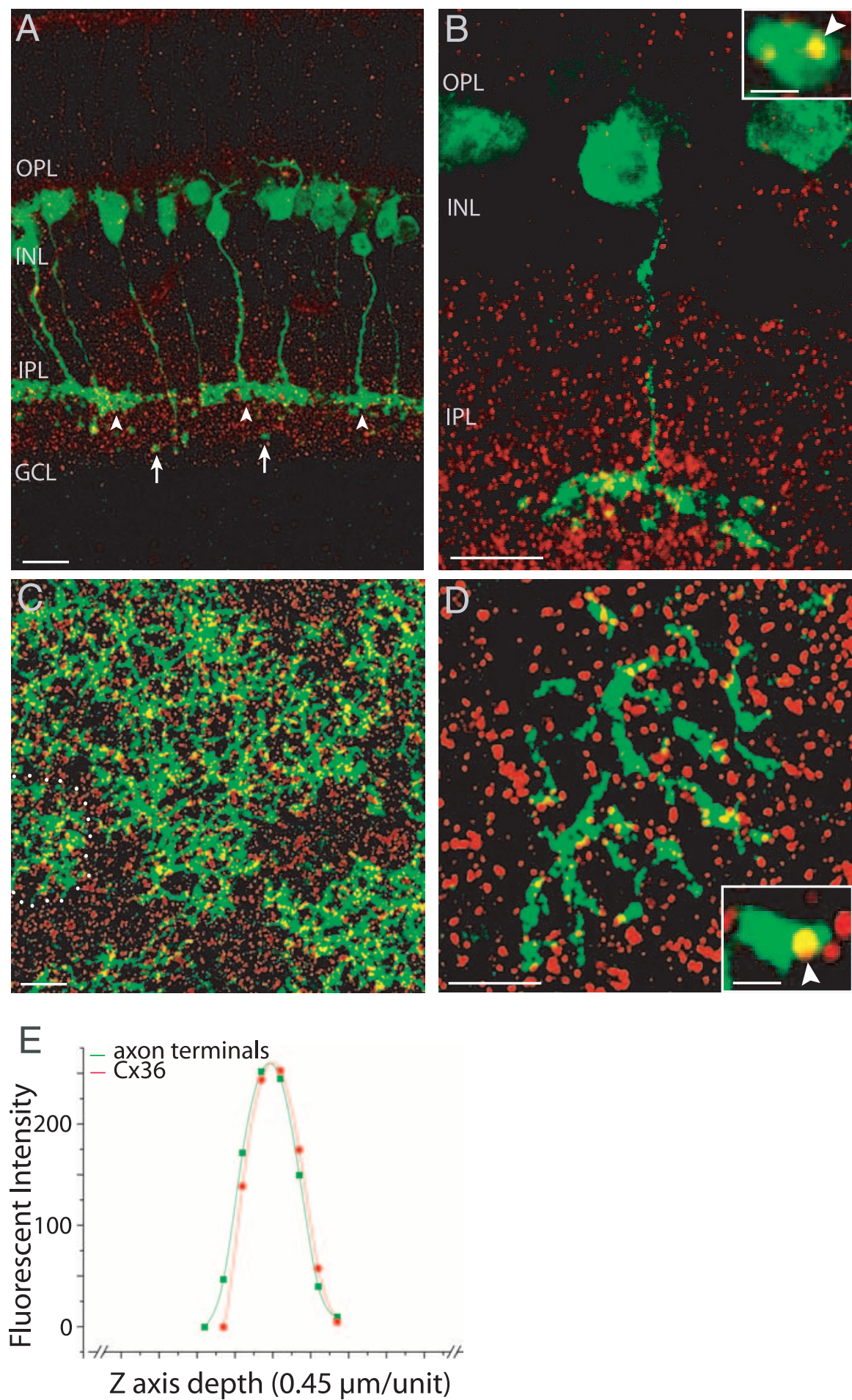

Figure 1. Expression of $\mathrm{C} \times 36$ in 357 bipolars of retinas. Strong colocalization (yellow) of (x36-immunoreactive puncta (red) with axon terminals of the GFP-positive 357 bipolars (green, arrowheads; arrows point to faint labeling of rod bipolars) are shown in low-power $(\boldsymbol{A})$ and high-power ( $\boldsymbol{B}$, arrowhead in inset) images of vertical sections as well as in low-power $(\boldsymbol{C})$ and high-power $(\boldsymbol{D}$, arrowhead in inset) images of flat-mount retinas. Note the low and irregular coverage of the retina by the 357 bipolars. One 357 bipolar (circle) has no overlap with any others, and many overlap on only one side. Scale bars: $20 \mu \mathrm{m}$; insets, $2 \mu \mathrm{m}$. E, Graph of pixel fluorescence intensity distributions of one $\mathrm{X} x 36$-immunoreactive punctum and 357 bipolars along the $z$-axis of images as a function of the z-axis depth. OPL, Outer plexiform layer; INL, inner nuclear layer; IPL, inner plexiform layer; GCL, ganglion cell layer.

$-1 \mathrm{nA}$ ) into individual AII amacrine cells, using a $63 \times$ water-immersion objective (Achroplan; Zeiss, Thornwood, NY). After microinjection, the slice was fixed for $30 \mathrm{~min}$ in 2\% PFA and rinsed in PB before additional immunostaining for $\mathrm{Cx} 36$.
Immunocytochemistry. The following primary antibodies were applied: rabbit anti-Cx36 (1:1000; Zymed, San Francisco, CA) and mouse anti-PKC $\alpha$ clone MC5 (1:100; Amersham Biosciences, Arlington Heights, IL). The retina was preincubated in a solution containing $10 \%$ normal goat serum (NGS), 1\% bovine serum albumin (BSA), and $0.5 \%$ Triton X-100 in PBS, $\mathrm{pH}$ 7.4, for $2 \mathrm{~h}$. The primary antibodies were diluted in 5\% NGS, $1 \%$ BSA, and $0.5 \%$ Triton $\mathrm{X}-100$ in PBS and applied for $3-5 \mathrm{~d}$ at $4^{\circ} \mathrm{C}$. After washes in PBS, secondary antibodies dissolved in $2 \%$ NGS and $0.3 \%$ Triton X-100 in PB were applied for $2 \mathrm{~h}$ at room temperature. Secondary antibodies were conjugated to either Alexa 488, Alexa 594 (Molecular Probes, Eugene, OR), or Cy5 (Jackson ImmunoResearch, West Grove, PA).

Dissociation of the retina. The methods for dissociation of the retina are based on those described previously (Jakobs et al., 2003). In brief, a piece of retina from the 357 mouse was incubated in $2 \mathrm{ml}$ of HBSS containing $0.5 \mathrm{mg} / \mathrm{ml}$ papain (Worthington, Lakewood, NJ) for 20 $\min$ at $37^{\circ} \mathrm{C}$. The reaction was then quenched using $2 \mathrm{ml}$ of minimal essential medium containing 5\% horse serum and $200 \mathrm{U} / \mathrm{ml}$ DNAseI (Sigma). Dissociated cells were obtained by trituration with a heat-polished Pasteur pipette, collected by centrifugation, and resuspended in Ringer's solution with $0.5 \%$ BSA at a density of $\sim 25,000$ cells $/ \mathrm{ml}$. The cell suspension was deposited on glass pretreated with poly-L-lysine (Sigma). For immunocytochemistry, the cells were washed in PB and fixed in 4\% PFA; unfixed cells were used for reverse transcription (RT)-PCR.

Single-cell RT-PCR. The isolation of single bipolar cells from the cell suspension was done on an Axiovert 200 microscope (Zeiss). The GFP-positive bipolars were identified, photographed with a CCD camera (Roper Scientific, Trenton, NJ), aspirated into a microcapillary, and washed in Ringer's solution. Then they were repicked with a fresh microcapillary and transferred into a thin-wall PCR tube. A negative control (50-100 $\mathrm{nl}$ of washing medium) was taken for every cell. Whole-retina mRNA served as a positive control. All controls were processed in parallel to the samples.

The single-cell RT-PCR was done in two steps. RT and the first-round PCR was done using the Access PCR kit (Promega, Madison, WI) in the presence of $2 \mu \mathrm{M}$ primers for $\mathrm{Cx} 36$, $\beta$-actin as a positive internal control, and rodopsin as a negative internal control. In addition, some samples were assayed for $\mathrm{Cx} 36$ and $\mathrm{Cx} 45$ simultaneously. The reaction conditions were as follows: $45 \mathrm{~min}$ at $48^{\circ} \mathrm{C}$ for RT and 19 cycles for $1 \mathrm{~min}$ at $94^{\circ} \mathrm{C}, 1 \mathrm{~min}$ at $60^{\circ} \mathrm{C}, 2 \mathrm{~min}$ at $68^{\circ} \mathrm{C}$, followed by a final extension step at $68^{\circ} \mathrm{C}$ for 7 min. The second PCR (31 cycles) was done for each PCR product separately. The reaction products of the second PCR were run on a $2 \%$ agarose gel, photographed, eluted from the gel using the Qiaex II kit (Qiagen, Hilden, Germany), and subjected to confirmatory restriction enzyme digestion with $\mathrm{XbaI}$. The primer sequences and lengths of expected amplicons were as follows: Cx36, ccagtaaggagacagaacca (forward), ctgccgaaattgggaacact 
(reverse), $457 \mathrm{bp}, \mathrm{XbaI}$ site at 255; rod-opsin, tacacactcaagcctgaggt (forward), cctggtgggtgaagatgtag (reverse), $265 \mathrm{bp}$. Two pairs of nested primers were used to amplify $\mathrm{Cx} 45$. The sequences of the outer primers were as follows: $\mathrm{Cx} 45$, agattgcctacaagcaaaaca (forward 1), gtacatacaaaaactgtccaaca (reverse 1), catcaccaaaacaacccccatg (forward 2), gttcttctctggatctggaagac (reverse 2). The length of the expected final PCR product is $380 \mathrm{bp}$. The primer sequences for the $255 \mathrm{bp} \beta$-actin fragment were described by Paarmann et al. (2000). The primer pairs for $\beta$-actin and rod-opsin spanned at least one exon/intron boundary; the primers for $\mathrm{Cx} 36$ and Cx45 anneal on the same exon. Therefore, control cells were assayed omitting the RT step or after pretreatment with RNAseA and run in parallel with the samples. Under these conditions, we never observed any bands, showing the RNA dependency of the amplification.

Confocal imaging and image analysis. A BioRad (Hercules, CA) Radiance confocal microscope equipped with a krypton-argon laser, Zeiss Plan Apochromat 25-/0.8 W, and C-Apochromat 40-/1.2 W and 63-/1.2 W lenses were used. Image acquisition was performed sequentially for all channels to rule out cross talk between red, green, and far-red channels.

To quantify the extent of overlap between the axon terminals of the 357 bipolars and the Cx36-immunoreactive puncta, $z$-stack images from flat-mount retinas were taken. The judgment of $x-y$-axis of images was based on direct observation. For each region, the Cx36immunoreactive puncta (red) that were completely surrounded in the $\mathrm{X}-\mathrm{Y}$ dimensions by a GFP-labeled axon terminal (green) were targeted. For this region $\left(\sim 20 \mu \mathrm{m}^{2}\right)$, the pixel fluorescence intensity in each confocal image of the z-stacks was measured, using the stack arithmetic function of Metaphorph (Universal Imaging Corporation, West Chester, PA), and plotted as a function of $z$-axis depth for red and green channels.

\section{Results}

The major goal in the present study was to address the question of whether or not any ON cone bipolar cells express Cx36, which would make possible homotypic gap junctions with AII amacrine cells. To achieve this goal, we took advantage of availability of a transgenic mouse in which one type of ON cone bipolars (357 bipolar cells) express a high level of GFP (Huang et al., 2003), to perform investigation of $\mathrm{Cx} 36$ expression in the axon terminals of this type of ON bipolar.

A polyclonal rabbit anti-Cx36 antibody, the specificity of which had been tested in previous studies (Mills et al., 2001), was used to label Cx36. GFP-expressing 357 bipolars (green, arrowheads) have axons terminating in the inner part (sublamina b) of the IPL, where dense Cx36-immunoreactive puncta (red) appeared (Fig. $1 A$ ). In these single-section images, faint labeling of rod bipolars is also observed (Fig. $1 A$, arrows) but is easily distinguished from cone bipolars. In sections, Cx36-immunoreactive puncta were found to colocalize with axons of the 357 bipolars (Fig. 1 $A, B$, yellow). In flat mounts, strong colocalization was seen along axons of the 357 bipolars (Fig. 1C,D, yellow). We performed a quantitative test to check the correspondence of axons and $\mathrm{Cx} 36$ puncta along the $z$-axis. Examples were selected bipolars. Scale bar, $5 \mu \mathrm{m}$.
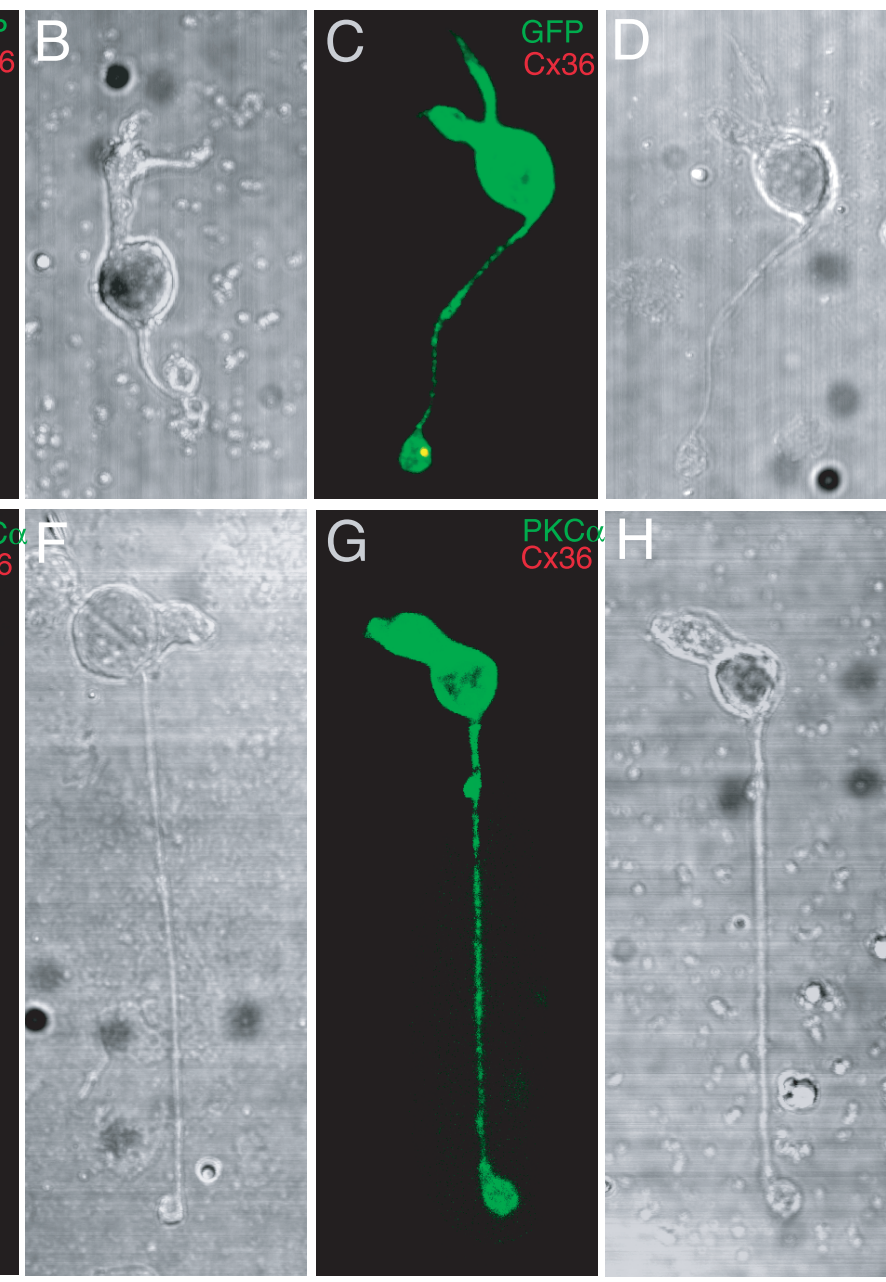

Figure 2. Expression of $\mathrm{C} \times 36$ in isolated 357 bipolars, not in isolated rod bipolars. $\boldsymbol{A}-\boldsymbol{D}$, Two isolated 357 bipolars labeled with E, , $\boldsymbol{G}, N_{0}$ Cx36-immunoreactive puncta colocalize with the rod bipolars (green). $\boldsymbol{F}, \boldsymbol{H}, \mathrm{DIC}$ images of the two same rod

in which a punctum and axon appeared to be completely colocalized (i.e., a yellow punctum was entirely surrounded in the $\mathrm{X}-\mathrm{Y}$ dimensions by axonal fluorescence). Fluorescence at that $\mathrm{X}-\mathrm{Y}$ position was then analyzed quantitatively in the $\mathrm{Z}$ dimension. A representative example is shown in Figure $1 E$, in which the distributions of pixel fluorescence intensity of a Cx36immunoreactive punctum and the surrounding 357 bipolar terminals almost overlap. Based on this finding, we conclude that Cx36 colocalize with the axons of the 357 bipolars.

In these images, Cx36 could belong to AII amacrines or ON cone bipolars, and the density of puncta was so high that it would be difficult to distinguish these colocalizations from chance correspondences. To separate the possibilities, we next labeled isolated individual 357 bipolars with the Cx36 antibody. In a total of 35 isolated 357 bipolars, 11 cells were found to have at least one Cx36-immunoreactive punctum in their remaining axonal terminals. This is most likely an underestimate of true frequency, because of the damage that occurs during dissociation. Figure 2 shows two examples of the isolated 357 bipolars (green) together with Cx36-immunoreactive puncta (Fig. $2 A, C$, red) and their differential interference contrast (DIC) images (Fig. $2 B, D$ ). The 357 bipolars preserved parts of their axon terminals after isolation, and their axonal terminals colocalize with Cx36- 

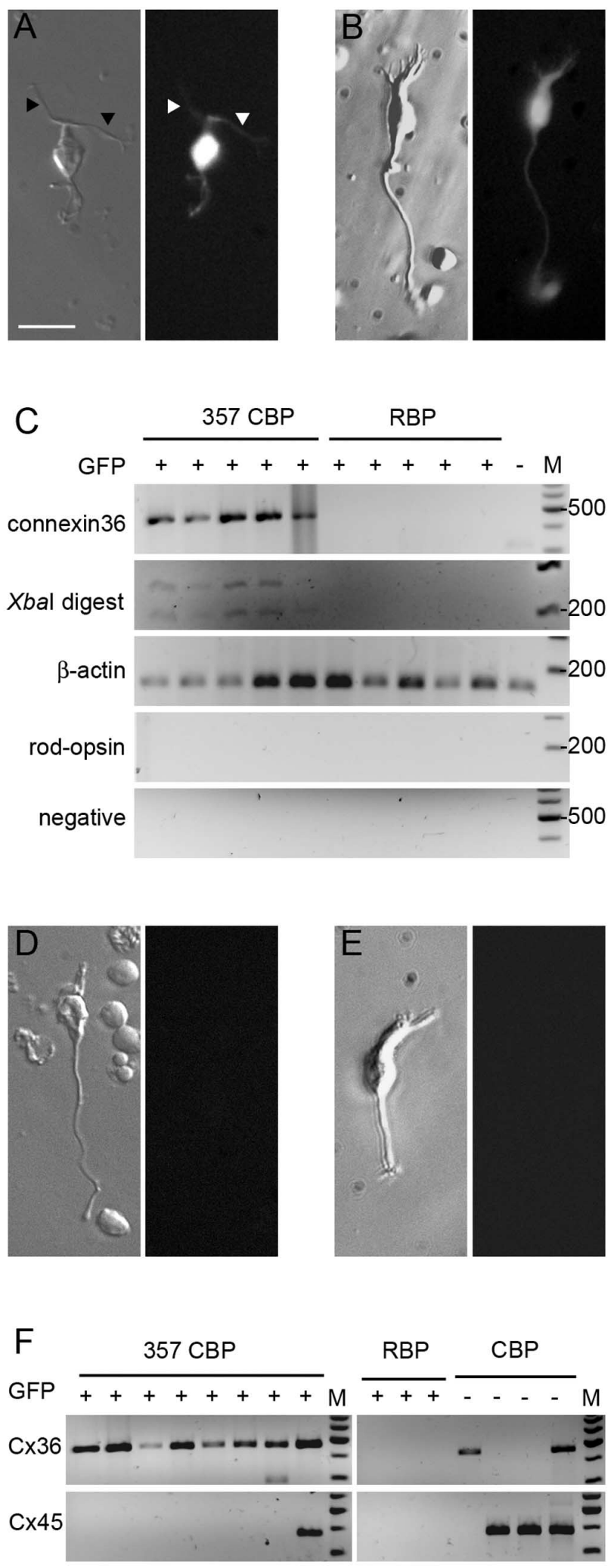

Figure 3. Agarose gel electrophoresis of single-cell RT-PCR products for $\mathrm{C} \times 36$ and $\mathrm{C} \times 45$ mRNA. $\boldsymbol{A}$, A typical GFP-expressing 357 bipolar is shown under Hoffman illumination and epifluorescence. The arrowheads indicate the characteristic long, thin dendrites of this cell type. $\boldsymbol{B}$, A typical rod bipolar cell, also positive for GFP. The long axon and the tuft of dendrites are clearly visible. $C$, Results of single-cell RT-PCRs from five 357 bipolars, five rod bipolar cells, and one GFP-negative bipolar cell. D, A typical GFP-negative cone bipolar cell that does not express Cx36. $\boldsymbol{E}$, The only example of a GFP-negative cone bipolar cell in our sample. It was (x36 positive. $\boldsymbol{F}$, Simultaneous RT-PCR of $\mathrm{Cx} 36$ and $\mathrm{Cx} 45$ from different types of bipolars. Scale bar, $20 \mu \mathrm{m}$. CBP, Cone bipolar cell; RBP, rod bipolar cell. immunoreactive puncta (Fig. 2A,C, yellow). Consistent with previous studies (Feigenspan et al., 2001; Mills et al., 2001), isolated rod bipolar cells $(n=20)$, labeled with $\operatorname{PKC} \alpha$, did not colocalize with Cx36-immunoreactive puncta. Two examples and their DIC images are shown in Figure $2 E-H$.

We verified Cx36 expression in the 357 bipolars by single-cell RT-PCR. After careful dissociation with papain, it is still possible to identify rod bipolars and cone bipolars by their characteristic morphology. These characteristics allowed us to clearly identify and collect these cells for RT-PCR analysis (Fig. $3 A, B$ ).

RT-PCR is vulnerable to false-negative and false-positive results because of cell loss during transfer and carryover of contaminating mRNA or cell debris, respectively. Therefore, every individual bipolar cell chosen for analysis was aspirated, expelled into fresh medium, repicked, and expelled into the PCR tube. Primers for positive ( $\beta$-actin) and negative (rod-opsin) internal controls were always included, and negative controls were taken from the washing medium.

Five 357 bipolars were assayed for Cx36 expression. Five rod bipolars and one GFP-negative bipolar were also analyzed as controls. We found Cx36 expression in all 357 bipolars but in none of the other cells (Fig. 3C). We analyzed six additional GFPnegative bipolars. One GFP-negative cone bipolar expressed Cx36, and others were negative. Two typical cells are shown in Fig. 3, $D$ and $E$.

We wanted to see whether 357 bipolars expressed Cx45 in addition to Cx36. Eight additional 357 bipolars, three rod bipolars, and four GFP-negative cone bipolars were assayed for both connexins simultaneously. All of the 357 bipolars expressed Cx36. One 357 bipolar was found to be also positive for $\mathrm{Cx} 45$. Although this could, in principle, indicate heterogeneity of 357 bipolars with respect to $\mathrm{Cx} 45$ expression, the more likely explanation is that we inadvertently collected more than one cell in this one case. In agreement with previous findings (Deans et al., 2002; Maxeiner et al., 2005), rod bipolars were negative for both connexins. Of the four GFP-negative cone bipolars, assayed under identical conditions, three were found positive for Cx45 (Fig. $3 F)$. Together, this indicates that rod bipolars express neither $\mathrm{Cx} 36$ nor $\mathrm{Cx} 45$ and that the situation is more complex for cone bipolar cells: 357 bipolars are Cx36 positive and Cx45 negative, whereas $\mathrm{Cx} 45$ was clearly detectable in some other cone bipolars, in accordance with the results of Maxeiner et al. (2005). A more detailed fractionation of the other cone bipolars (i.e., a correlation of their morphology with connexin expression) was not undertaken.

Finally, we microinjected individual AII amacrine cells in retinal slices of the 357 mice, using sharp microelectrodes filled with Alexa Fluor 594. AII amacrine cells that were close to a GFPpositive 357 cell were chosen for microinjection. Figure 4 shows one sample of injected AII amacrine cells (red) that has characteristic lobular appendages in sublamina a of the IPL and fine dendrites in the sublamina $b$, together with a GFP-positive 357 cell (green) and Cx36 immunoreactivity (blue) in a slice. Consistent with the previous studies, Cx36 immunoreactivity is associated with the dendrites of the AII amacrine cell (Fig. $4 A$, arrows), and Cx36 puncta appear in the dendrites of the AII amacrine cell (Fig. $4 A$, arrows) and with the axonal terminals of the 357 bipolar (Fig. $4 B$, arrows). High-magnification views of single optical sections demonstrate $\mathrm{Cx} 36$ puncta colocalized with both the AII amacrine cell dendrites (Fig. $4 a$, arrowheads) and the axonal terminals of the 357 bipolar (Fig. $4 b$, arrowheads) at their sites of contact (Fig. $4 c$, arrowheads). Because of limits to the resolution of light microscopy, it is not possible unequivocally to assign 
these puncta to one cell or the other: because the 357 bipolars and AII both express $\mathrm{Cx} 36$, they are most likely homotypic Cx36-Cx36 junctions, but they could, in principle, be junctions that contain $\mathrm{Cx} 36$ and some other hemichannel.

\section{Discussion}

All of our results indicate that the $357 \mathrm{ON}$ cone bipolar cells in the mouse retina express Cx36. It is conceivable but unlikely that the 357 bipolar cells make Cx36Cx36 junctions with each other. The sparse mosaic of these bipolar cells, like many others, creates a coverage factor of less than unity (Mills and Massey, 1992; Milam et al., 1993; Massey and Mills, 1996; Brown and Masland, 1999; Chan et al., 2001). A consequence is that most 357 bipolars have slight axonal overlap with another 357 bipolar; indeed, some cells have no overlap at all and thus cannot make gap junctions with another 357 bipolar.

Instead, it seems likely that the type 357 bipolar makes a Cx36-Cx36 junction with the AII amacrine cell. AII amacrine cells are known to express Cx36, type 357 bipolars are now shown to express $\mathrm{Cx} 36$, and type 357 bipolars contact AII at a junction at which Cx36 is expressed by at least one of the partners (Fig. 4). Although one can perhaps imagine a scenario in which another type of junction could exist, the most straightforward inference is that the junction is homotypic.

A recent study (Maxeiner et al., 2005) has shown that some ON bipolars express $\mathrm{Cx} 45$ but that these are only a subset of the total population of ON bipolars. Furthermore, their results show that glycine diffuses from AII amacrine cells into bipolar cells in a Cx45(-/-) mouse [Maxeiner et al. (2005), their Fig. 7B]. Tissue staining by Deans et al. (2002) demonstrated that some ON cone bipolars, but not all of them, express Cx36 (their Figs. 2, 3). There is no contradiction between these two previous studies, nor do either conflict with the present results: certain type of ON cone bipolar cells appear to express $\mathrm{Cx} 36$ at their gap junction with AII amacrine cells, whereas others express Cx45.

The intriguing question raised by this finding is why it would be desirable for different types of $\mathrm{ON}$ cone bipolars to use different gap-junctional proteins. A possibility is that the reason has to do with the physiological parallelism of bipolar cell channels. The various types of bipolar cell are believed to have different physiological properties. Similarly, gap junctions that are assembled from different connexins function differently in gating, singlechannel conductance, and permeability (for review, see Bennett and Zukin, 2004). Assuming, as seems likely, that most types of ON cone bipolar cells form gap junctions with the AII amacrine cell, a current possibility is that some communicate via $\mathrm{Cx} 36-$ Cx36 junctions and some via Cx36-Cx45 junctions. Perhaps the two types of gap junction have physiological or regulatory properties (Mills and Massey, 1995, 2000) matched to the specific functions of particular types of bipolar cells.

\section{References}

Bennett M, Zukin R (2004) Electrical coupling and neuronal synchronization in the mammalian brain. Neuron 41:495-511.

Brown SP, Masland RH (1999) Costratification of a population of bipolar cells with the direction selective circuitry of the rabbit retina. J Comp Neurol 408:97-106.

Chan TL, Martin PR, Grünert U (2001) Immunocytochemical identification and analysis of the diffuse bipolar cell type DB6 in macaque monkey retina. Eur J Neurosci 13:829-832.

Deans M, Volgyi B, Goodenough D, Bloomfield S, Paul D (2002) Connexin36 is essential for transmission of rod-mediated visual signals in the mammalian retina. Neuron 36:703-712.

Famiglietti EV, Kolb H (1975) A bistratified amacrine cell and synaptic circuitry in the inner plexiform layer of the retina. Brain Res 84:293-300.

Feigenspan A, Teubner B, Willecke K, Weiler R (2001) Expression of neuronal connexin36 in AII amacrine cells of the mammalian retina. J Neurosci 21:230-239

Feigenspan A, Janssen-Bienhold U, Hormuzdi S, Monyer H, Degen J, Sohl G, Willecke K, Ammermuller J, Weiler R (2004) Expression of connexin36 in cone pedicles and OFF-cone bipolar cells of the mouse retina. J Neurosci 24:3325-3334.

Ghosh K, Bujan S, Haverkamp S, Feigenspan A, Wassle H (2004) Types of bipolar cells in the mouse retina. J Comp Neurol 469:70-82.

Güldenagel M, Ammermuller J, Feigenspan A, Teubner B, Degen J, Sohl G, Willecke K, Weiler R (2001) Visual transmission deficits in mice with targeted disruption of the gap junction gene connexin36. J Neurosci 21:6036-6044.

Huang L, Shanker YG, Dubauskaite J, Zheng JZ, Yan W, Rosenzweig S, Spielman AI, Max M, Margolskee RF (1999) G $\gamma 13$ colocalizes with gustducin in taste receptor cells and mediates IP3 responses to bitter denatonium. Nat Neurosci 2:1055-1062. 
Huang L, Max M, Margolskee RF, Su H, Masland RH, Euler T (2003) The G protein subunit G $\gamma 13$ is co-expressed with $\mathrm{G} \alpha \mathrm{o}$ and $\mathrm{G} \beta 3$ in retinal On bipolar cells. J Comp Neurol 455:1-10.

Jakobs T, Ben Y, Masland R (2003) CD15 immunoreactive amacrine cells in the mouse retina. J Comp Neurol 465:361-371.

Kolb H, Famiglietti EV (1974) Rod and cone pathways in the inner plexiform layer of the cat retina. Science 186:47-49.

Massey SC, Mills SL (1996) A calbindin-immunoreactive cone bipolar cell type in the rabbit retina. J Comp Neurol 366:15-33.

Massey SC, Mills SL (1999) Gap junctions between AII amacrine cells and calbindin-positive bipolar cells in the rabbit retina. Vis Neurosci 16:1181-1189.

Maxeiner S, Dedek K, Janssen-Bienhold U, Ammermuller J, Brune H, Kirsch T, Pieper M, Degen J, Kruger O, Willecke K, Weiler R (2005) Deletion of connexin 45 in mouse retinal neurons disrupts the rod/cone signaling pathway between AII amacrine and ON cone bipolar cells and leads to impaired visual transmission. J Neurosci 25:566-576.

Milam AH, Dacey DM, Dizhoor AM (1993) Recoverin immunoreactivity in mammalian cone bipolar cells. Vis Neurosci 10:1-12.

Mills S, Massey S (2000) A series of biotinylated tracers distinguishes three types of gap junction in retina. J Neurosci 20:8629-8636.
Mills SL, Massey SC (1992) Morphology of bipolar cells labeled by DAPI in the rabbit retina. J Comp Neurol 321:133-149.

Mills SL, Massey SC (1995) Differential properties of two gap junctional pathways made by AII amacrine cells. Nature 377:734-737.

Mills SL, O’Brien JJ, Li W, O’Brien J, Massey SC (2001) Rod pathways in the mammalian retina use connexin 36. J Comp Neurol 436:336-350.

Paarmann I, Frermann D, Keller B, Hollmann M (2000) Expression of 15 glutamate receptor subunits and various splice variants in tissue slices and single neurons of brainstem nuclei and potential functional implications. J Neurochem 1335-1345.

Pignatelli V, Strettoi E (2004) Bipolar cells of the mouse retina: a gene gun, morphological study. J Comp Neurol 476:254-266.

Sterling P (1998) Retina. In: The synaptic organization of the brain (Shepherd GM, ed), pp 205-253. New York: Oxford UP.

Strettoi E, Raviola E, Dacheux RF (1992) Synaptic connections of the narrow-field, bistratified rod amacrine cell (AII) in the rabbit retina. J Comp Neurol 325:152-168.

Strettoi E, Dacheux R, Raviola E (1994) Cone bipolar cells as interneurons in the rod pathway of the rabbit retina. J Comp Neurol 347:139-149.

Wässle H, Boycott BB (1991) Functional architecture of the mammalian retina. Physiol Rev 71:447-480. 